\title{
PENCIPTAAN MUSIK KERONCONG DAN WAYANG INOVATIF DALAM PERTUNJUKAN CONGWAYNDUT
}

\author{
Eko Aprianto Romadona \\ Sebagai Musisi di Kelompok Wayang CongWaynDut \\ Tinggal di Karanganyar, Jawa Tengah \\ Email : apri30971@gmail.com|081542685594
}

\begin{abstract}
Congwayndut is one of the puppet groups whose performances depart from the traditional wayang (puppetry) style. The wayang play itself belongs to the comedy genre. Nevertheless, the stories presented are still adopted from the stories of Ramayana and Mahabarata. There are some interesting things to be used as discourse materials from Congwayndut, whose accompaniment belongs to the so-called keroncong music, while the duration of the music is shortened to two or three hours. The sanggit of the Ramayana and Mahabarata puppet stories are also interpreted humorouslyand "exibly. This paper reveals the musical facts in the puppet group, that keroncong music is able to give its own impression as pakeliran music. Then, the celloin keroncong music is able to provide a distinctive aesthetic touch toaccompany the war scene. Besides that, it also discussed the performance sketches of the Congwayndut group.
\end{abstract}

Keywords: congwayndut, wayang keroncong, innovative shadow puppet.

\section{Pendahuluan}

Keroncong Wayang Gendut atau yang selanjutnya disebut dengan Congwayndut, adalah kelompok wayang keroncong asal Solo. Debutnya sebagai kelompok seni dimulai pada 25 Agustus 2010 .

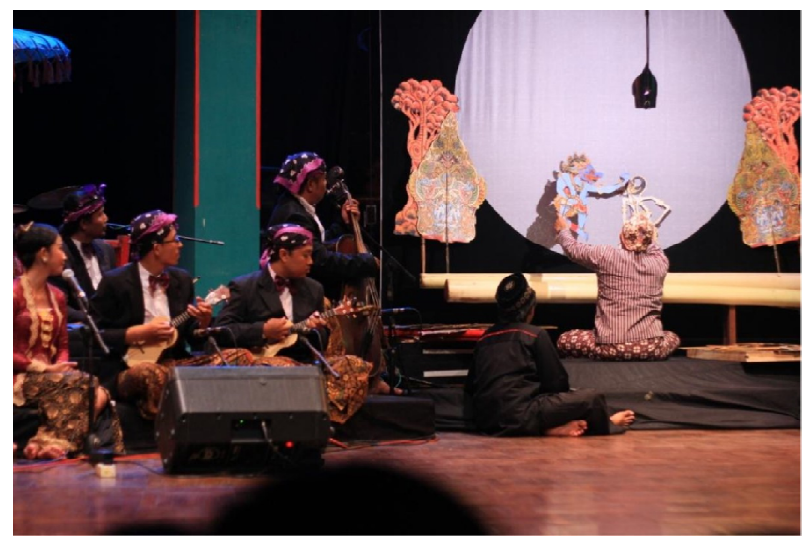

Gambar 1. Pementasan Congwayndut. (Foto: Joko Suyanto, 2016).

Congwayndut menggunakan wayang purwa sebagaimedianya. Lazimnya, wayang purwa diiringi dengan karawitan, namun tidak demikian dengan Congwayndut, kelompok tersebut menggunakan musik keroncong sebagai iringanannya.

Berbagai event telah "disinggahi" oleh kelompok wayang yang diprakarsahi oleh Dwi Suryanto itu. Seperti Hari Wayang Dunia (HWD), Solo Keroncong Festival(SKF), Festival Wayang Jawa Tengah, malam inagurasi pemilihan putra-putri Solo, serta Pager Desa di Wonogiri. Rentetan peristiwa tersebut membuat nama Congwayndut makin dikenal oleh masyarakat. Eksistensinya sebagai kelompok seni semakin dikenal ketika Congwayndut terlibat dalam misi kesenian Indonesia ke Singapura.

Naskah penelitian ini, difokuskan pada elemen musiknya. Hal apa yang patut dijadikan persoalan? Pertama, lazimnya di dunia perwayangan, pembabakan cerita ditandai dengan pathet dan serta sajian gendhing, lain halnya dengan Congwayndut, mereka menggunakan musik keroncong yang berperan sebagai ilustrasi dalam adegan, tak jarang juga menjadi theme song. Kedua, jika adegan perang pada wayang umumnya diiringi oleh kendhang, dalam 
Congwayndut memanfaatkan pola cello sebagai iringan adegan perangnya. Ketiga, lagu-lagu yang disajikan mengadopsi dari lagu yang telah populer di tengah masyarakat, baik itu bergenre pop, dangdut, rock, langgam, serta keroncongan.

Formasi awal, pada tahun 2010, Congwayndut menggunakan musik keroncong kelompok Swastika, dan itu berjalan selama 4 tahun. Akhir tahun 2014, terjadi perubahan formasi, meskipun tetap menggunakan idiom musik keroncong, namun terdapat tambahan alat musik perkusi, saxophone, gitar elektrik, dan bass elektrik. Sejak itu formasi Congwayndut memiliki kebaruan dalan aspek musikal. Lebih lanjut, awal tahun 2015, merupakan tahun di mana Congwayndut mulai dikenal oleh publik karena sering melakukan promo pentas, atau dalam komunitas tersebut menyebutnya dengan istilah "serangan pentas". "Serangan pentas" adalah promo pentas yang tidak bersifat memfinansial. Tujuannya agar publik mengetahui telah hadir wayang dengan inovasi baru, yang menjadi tontonan alternatifanak-anak muda.

Inovasi yang dilakukan Congwayndut adalah upaya konservasi terhadap kesenian wayang, terutama agar diminati generasi muda. Alihalih sebagai terobosan, nyatanya justru mampu memberikan efek signifikan terhadap generasi milenial tersebut. Hal itu ditandai dengan hadirnya Congwayndut diberbagai acara seperti: Malam Inagurasi Putra Putri Solo tahun 2016; "Closing Solo Great Sale 2017”, Susur Kampung Solo Raya dengan tajuk "Congwayndut 17an" pada 2017 yang lalu, diadakan di kabupaten se-Solo Raya. Selain itu juga melakukan talk show di beberapa media dan radio: Solopos, Radar Solo, Solo Radio dan Radio JPI. Kiprahya sebagai kelompok seni makin moncer ditandai dengan hadirnya Congwayndut diberbagai gelaran pentas seni, seperti: "Hari Teater Dunia", Hari Tari Dunia, Serta Hari Wayang Dunia, setiap tahunnya, pentas di Malaya Heritage Singapura 2016, sebagai peraih Hibah Kelola Seni Inovasi tahun 2017, Maha Karya Borobudur 2018, tour konser bersama Intrafood dalam "Intra Budaya" di 5 kota: (1) Madiun, (2) Yogyakarta, (3) Magelang dan(4) Purwokerto dan (5) masih banyak lagi.
Lebih lanjut, Congwayndut juga secara resmi terdaftar sebagai organisasi di bawah naungan pemerintah Kabupaten Karanganyar pada tahun 2016 sebagai sanggar seni dan telah memiliki akta pendirian organisasi dari notaris. Sanggar Congwayndut tepatnya berada di Dusun Jetis, Suruh , Tasikmadu, Karanganyar.

\section{Karya Congwayndut}

Congwayndut mempunyai beberapa karya yang telah mewarnai pergelaran seni di beberapa tempat. Karya-karya Congwayndut meliputi dua model sajian: karya wayang dan karya musik.

\begin{tabular}{|c|c|}
\hline KARYA MUSIK & KARYA WAYANG \\
\hline $\begin{array}{l}\text { 1. Musik Tari "Semarak Budaya } \\
\text { Indonesia", tahun } 2016 \text { (Surakarta) } \\
\text { 2. Festival Keroncong Surakarta, tahun } \\
2016 \text { "Gamelan Akbar", tahun } 2015 \\
\text { 3. Musik "Garta) } \\
\text { (Surakarta) } \\
\text { 4. Musik Tari "Ramayana Art Summit", } \\
\text { tahun } 2014 \text { (Surakarta) } \\
\text { 5. Musik Teater Lungid,"Gundala Putra } \\
\text { Petir" tahun } 2013 \text { (Surakarta) } \\
\text { 6. Musik "Ramayana Kontemporer" } \\
\text { tahun } 2013 \text { (Art Sammit Indonesia) } \\
\text { 7. Musik "Opening SIPA", tahun 2013 } \\
\text { (Semarak Candra Kirana) } \\
\text { 8. Musik "Kiskendha Kandha" tahun } \\
\text { 2013 (Festival Ramayana } \\
\text { Internasional) } \\
\text { 9. Musik Tari "Macan Ganjur", tahun } \\
\text { 2013 (Universitas Negeri Semarang) } \\
\text { 10. Musik Tari "Bedaya Amplop", tahun } \\
\text { 2013 (Hari Tari Dunia) "Ramayana } \\
\text { 11. Musik Tari } \\
\text { Kontemporer", tahun 2011 (ISI } \\
\text { Surakarta) }\end{array}$ & $\begin{array}{l}\text { 1. "Anoman SMS", tahun } 2010 . \\
\text { 2. "In Love", tahun } 2010 \\
\text { 3. "Wisanggeni Wae Piye?", tahun } \\
2011 . \\
\text { 4. "Alap-alapan Jenakawati", tahun } \\
\text { 2011. } \\
\text { 5. "Bisma", tahun 2012. } \\
\text { 6. "Sang Kumbakarna", tahun } 2012 . \\
\text { 7. "Ajaran Sotasoma“, tahun } 2013 . \\
\text { 8. "Sang Tetuka", tahun } 2013 . \\
\text { 9. "Jorosando", tahun } 2013 . \\
\text { 10. "Hanoman" tahun } 2014 . \\
\text { 11. "Wisanggeni Lahir", } 2014 . \\
\text { 12. "Partadewa", tahun 2014. } \\
\text { 13. "Pahlawan Tanpa Tanda Jasa", } \\
\text { tahun 2015. } \\
\text { 14. "Semar Mbangun Desa", tahun } \\
\text { 2015. } \\
\text { 15. "Dalang Keblegan Kelir" tahun } \\
\text { 2015. } \\
\text { 16. "Cintaku di Negerimu", tahun } 2016 . \\
\text { 17. "Digege Mangsa", tahun } 2016 . \\
\text { 18. "Selo Adha", tahun } 2016 . \\
\text { 19. "Anoman Si Kethek Putih", tahun } \\
\text { 2016. }\end{array}$ \\
\hline
\end{tabular}

\section{Karya Musik Karya Wayang}

Penciptaan Seni. Bagian ini menarik apabila disimak pernyataan I Wayan Sadra dalam Waridi (ed.) tentang konsep penciptaan musik yang disebut sebagai konsep "mencipta musik dalam rangka" yaitu untuk apa musik itu diciptakan? (2005: 78). Ungkapan Sadra tentang mencipta musik digunakan untuk mengetahui latar belakang penciptaan musik dalam komunitas Congwayndut. Latar belakang penciptaannya penting diketahui untuk mengetahui bahan sekaligus melihat cara mengkonstruksi musikalnya. Alasan-alasan pemilihan pola-pola sekaligus nada-nada menjadi ulasan yang menjadi episode menarik dalam tulisan ini. Dalam rangka kepentingan tersebut menarik jika disimak opini Bambang Sunarto berikut ini. 
Mencipta sebuah seni, terdapat empat hal yang menjadi dasar penting dalam proses penciptaan. Menurut Bambang Sunarto dalam bukunya Epistemologi Penciptaan Seni, dinyatakan demikian. Kegiatan penciptaan seni, adalah proses mencari unsur konstruksi musik mengenai (1) keyakinan seniman dalam berkarya, (2) vokabuler dan model-model artistik, (3) konsep-konsep artistik dan (4) model artistik, yang selanjutnya digunakan sebagai sarana dalam mewujudkan karya seni (Sunarto, 2013:41)

Dari uraian di atas, dapat ditarik pemahaman bahwa rangkaian menciptakan seni, bekalnya adalah pengetahuan empiris mengenai seni itu sendiri. Pengetahuan atas artistik digunakan sebagai modal untuk menciptakan sebuah seni yang baru. Oleh karena itu, hasil ciptaan itu selalu mewakili isi kepala dari seniman tentang persepsi estetikanya (Sunarto, 2013: 42).

Sketsa penciptaan musik Congwayndut, ditempuh melalui berbagai kegiatan. Empat landasan penting yang dinyatakan Sunarto di atas, yang digunakan untuk mengungkap proses penciptaan musik Congwayndut. Keyakinan dasar terjadi di dalam dirikreator musik dan sang dalang. Sementara vokabuler adalah refleksi pengalaman sang kretaor bunyi yang digunakan untuk menyusun musik. Konsep adalah gagasan tentang musik yang disusun. Sementara model adalah, struktur atau bagan musik seperti apa yang akan dicipta. Skema alur konseptual di atas dapat dilihat dalam bagan berikut ini.

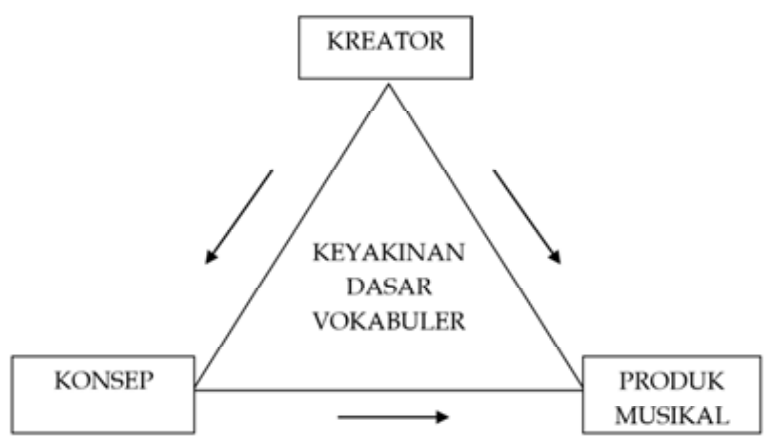

Bagan 1. Skema alur penciptaan musik Congwayndut.

Bagan diadopsi dari konsep Bambang Sunarto.

\section{Tahap Kompositoris Musik Congwayndut}

Bagian ini memuat penjelasan tentang prosedur yang dilaksanakan dalam proses kegiatan penciptaan karya seni, yaitu musik. Di dalamnya diungkap hal-hal yang berkenaan dengan tata cara yang dilakukan dalam mencipta karya seni. Menyusun komposisi baru karawitan merupakan salah satu sarana atau cara seniman untuk menghasilkan produk seni. Masing-masing seniman memiliki cara atau prosedur tersendiri dalam menyusun karya sesuai dengan kebiasannya (Sukerta 2011, 67). Congwaydnut secara composing memiliki caranya sendiri dalam menyusun musik. Cara itu ditentukan oleh Sang dalang yaitu Dwi Suryanto. Praktik menyusun tahapan musik tersebut dibantu oleh beberapa musisi seperti: Danis Sugianto, Muhammad Subhan, Dwi Hardjanto, Aji Agustian, dan Nurseto Bayu Aji. Mereka adalah pemikir di bidang musik Congwayndut yang bertugas menerjemahkan ide musikal dari Dwi Suryanto. Bunyi atau musik yang disusun Congwayndut memenuhi kebutuhan musik untuk naskah yang dibuat sang dalang.

\section{Memilih Bahan}

Bagian ini adalah tahapan di mana penentuan bahan atau memilih material yang digunakan untuk membuat musik. Menentukan bahan berkaitan dengan pilihan sumber bunyi, genre musik apa yang dipilih, serta konsep garap apa yang akan diguanakan untuk menyusun musik, dan pertimbangan musisi. Rentetan peristiwa tersebut adalah langkah awal yang penting dalam rangka menciptakan bunyi musik. Memilih bahan sepenuhnya berada pada otoritas sang dalang yaitu DwiSuryanto.

Di dalam struktur musik Congwayndut, terdapat tiga model musik yang menjadi konsep garapanya, yaitu musik keroncong, kontemporer, serta combo band. Tiga genre musik tersebut kemudian diolah menjadi model musik yang memiliki karakter kuat sebagai musik pakeliran gaya Congwayndut. Karakter musik yang terdiri dari tiga gabungan genre musik tersebut, yang kemudian menjadi ciri khas musik pakeliran wayang 
Congwayndut. Tiga genre tersebut dipilih bukan tanpa pertimbangan, terdapat tendensi penting yang melingkupi pemilihan jenis musik tersebut, yaitu: kompetensi, memenuhi selera generasi muda, dan tawaran konsep musikal baru dalam dunia pakeliran wayang, khususnya wayang inovatif.

Ide musik keroncong, secara garap dipimpin oleh Danis Sugianto seniman sekaligus akademisi musik, yang puluhan tahun malang melintang di dunia musik keroncong dan Sutopo (Si Doel), seniman keroncong sekaligus komedian asal Solo.

\section{a. Keroncong}

Awal mula Dwi Suryanto memainkan wayang dengan iringan keroncong adalah pertemuannya dengan kelompok keroncong terkenal asal Surakarta yaitu kelompok Swastika. Pertemuan tersebut diinisiasi oleh Danis Sugiyanto yang juga personil Keroncong Swastika. Pertemuannya tersebut lantas berlanjut dalam sebuah konsep pertunjukan wayang dengan menggunakan musik pakeliran keroncong. Sejak itu akhirnya terbentuklah Congwayndut.

Bersama Swastika, Congwayndut menapaki karier kesenimannya dengan garapan musik full keroncong. Lagu-lagu yang disajikan merupakan lagu-lagu keroncong yang telah populer. Dengan Swastika, sudah pentas di berbagai event di Kota Surakarta selama kurang lebih satu tahunan. Setelah itu masing-masing pemusik memiliki kesibukan dan projek musik dan perjalanan dengan Swastika dicukupkan. Akhirnya Dwi Suryanto bersama Danis Sugiyanto dipertemukan dengan alumni Etnomusikologi dan terbentuklah Congwayndut dengan formasi musik saat ini.

Kisah masuknya musik keroncong justru menjadi akar dari terbentuknya kelompok Congwayndut sebagai iringan wayang inovatif. Pertemuannya dengan formasi yang baru tersebut, ternyata merupakan musisi dan komposer-komposer muda di lingkungan ISI Surakarta, seperti: Muhammad Subhan, Dwi Hardjanto, Yeni Arama, Aji Agustian, dan Nurseto Bayu Aji. Hadirnya personil baru dengan latar belakang musikal yang beragam, secara berlahan memberikan keleluasaan sang dalang untuk semakin luas dalam mengembangkan gaya musiknya. Meskipun tetap menggunakan keroncong sebagai pilar musikalnya, namun pengembangan dengan gaya kontemporer dan combo band menjadi upaya eksperimental sang dalang.

Secara kompositoris, genre keroncong diprakarsahi oleh Danis Sugiyanto. Kendati demikian, personilyang lain seperti: Ajiagustian, Oky Prasetyo, dan Eko Aprianto juga memiliki pengalaman dalam dunia keroncong, jadi secara proses menggarapan musik, tidak memiliki kendala yang begitu berarti. Apa yang diinstruksikan sang kreator musik, personil yang lain menterjehmahkan dengan baik. Musik keroncong yang terdapat dalam Congwayndut, memiliki dua jalur garapan, yang pertama adalah keroncong klasik yang kedua adalah keroncong kreasi. Keroncong klasik adalah garapan musik yang menyajikan lagu-lagu keroncong yang sudah ada, seperti langgam keroncong, dengan lagu, Jembatan Merah, Sepasang Mata Bola, dan lain sebagainya.

Sementara keroncong kreasi adalah keroncong yang digabungkan dengan alat musik serta beat genre musik lain seperti blues, jazz, swing, dan rock. Perpaduan tersebut sebagai upaya eksplorasi musikalitas para pemain Congwayndut yang mayoritas adalah seorang komposer muda. Keroncong kreasi atau keroncong modern tersebut menyajikan lagu-lagu yang sudah populer di kalangan masyarakat, baik itu pop maupun dangdut.

\section{b. Musik Kontemporer}

Selain keroncong, Congwayndut juga mengadopsi gaya musik kekinian atau gaya musik kontemporer, dengan pendekatan menggunakan gaya musik Barat. Letak gaya musik ini berada dalam wilayah garap struktur yang melibatkan unsur musik keroncong, tembang Jawa, musik Barat dan lain sebagainya menjadi satu garapan yang bervariasi. Garapan musik bagian inilah yanag menandai ciri khas Kelompok Congwayndut menjadi unik dibanding dengan kelompok wayang yang lainnya.

Garapan musik ini secara menonjol muncul pada bagian-bagian tertentu seperti sajian musik transisi dan musik ilustrasi. Semua sajian musik transisi dan musik ilustrasi dilakukan secara mandiri 
dengan gaya dan kreasi Congwayndut. Oleh karena itu aspek kompositoris pada bagian ini yang paling menonjol karena banyak permainan sukat, dinamika, serta kepekaan musikal yang tinggi.

Konsekuensi dari musik garapan yang kekinian, akhirnya gerakan wayangpun juga turut dikembangkan, seperti di bagian jogetan dengan sekaran garapan sendiri. Wayang secara gesture memiliki keunikan tersendiri, jika dilihat secara seksama seperti pertunjukan wayang yang tidak mungguh. Konsepnya memang didesain dengan tajuk wayang alternatif, selain menyimpang dari pakem, di sisi lain menawarkan terobosan-terobosan model pertunjukan wayang yanag efektif. Kebanyakan penikmat pertunjukan menilai bahwa, kekuatan Congwayndut justru terletak di wilayah musik. Mayoritas penonton menyatakan, bahwa musik menjadi daya tarik tersendiri. Secara teknis memang cerita atau lakon dibawakan sangat fleksibel dan santai, yang paling utama adalah kekompakan musik, serta kekonyolan dalang saat membawakan cerita.

\section{c. Combo Band}

Selanjutnya adalah garapan musik gaya musik Barat. Bagian ini adalah bagian di mana musik disajikan untuk menarik para generasi muda, agar tertarik dengan Congwayndut. Format band terdiri dari gitar elektrik, bass elektrik, taganing sbagai pengganti drum set, kemudian saxophone. Alat musik yang telah disebut di depan tersebut adalah kerangka yang membentuk garapan combo band. Meskipun alat musik yang lain juga memberikan warna, namun perannya sangat minoritas. Bagian garapan musik combo biasanya digunakan untuk membawakan lagu-lagu populer yang bergenre rock atu pop. Namun secara kompositoris biasanya digabungkan dengan elemen keroncong, agar tidak meninggalkan konsepnya yaitu wayang keroncong. Garapan musik inilah yang secara konseptual dapat secara ekplisit menyasar kepada generasi muda, agar wayang dapat lagi dekat dengan mereka. Melalui pendekatan musik yang bernuansa pop art atau kreasi anak muda.
Gaya Congwayndut dalam bermusik memang sangat serius dalam hal aransemen, bertolak belakang dengan pembawaan lakon yang disampaikan oleh dalang. Namun keduanya memiliki ikatan atau relasi konseptual yang koheren, antara musik dengan alur cerita. Konsep combo band dihadirkan tujuannya untuk memberikan stimulan kepada penonton kaula muda.

\section{Mengolah Bahan}

Tahap ini, adalah tahap di mana bahan akan diracik menjadi sebuah produk, kaitannya dalam hal ini adalah karya musik. Tahap mengolah adalah wilayah eksperimental sekaligus laboratorium. Biasanya tahapan ini diwujudkan dengan kegiatan latihan bersama pendukung karya. Latihan dapat berupa apa saja termasuk menterjemahkan maksud Sang dalang terhadap bunyi, mengkonstruksi bunyi yang sudah ada menjadi bangunan musik yang diinginkan oleh dalang, dan eksplorasi bunyi serta pola yang sesuai dengan konsep yang telah tertulis dalam naskah. Rangkaian itu semua merupakan bagian dari mengolah bahan menjadi produk jadi, yaitu karya musik Congwayndut. Seperti yang dinyatakan oleh Dwi Suryanto berikut ini.

“...mengolah bahan kui, jan jane mung kegiatan latihan, goleki musik sing penak dienggo ngepasne suasana adegan. Latihan gawe musike ora nganggo wayang, pedomane mung alur cerita. Neng kene iki konco-konco tak kon menafsir musik sing pas go adegan sing wes tak gawe...golek i sing pas lan kepenak, segala model musik dicoba ning kene, dadi yo bolan baleni nganti menak..."(wawancara, 21 April 2018).

Terjemahan bebas:

[...mengolah bahan itu, sebenarnya hanya kegiatan latihan, mencari musik yang enak untuk dipakai dalam suasana adegan. Latihan membuat musik tidak menggunakan wayang, pedomannya hanya alur cerita. Di sini temanteman saya suruh menafsir musik yang pas untuk adegan yang sudah saya buat...mencari yang pas dan enak, semua 
jenis musik dicoba di sini, jadi ya diulang terus sampai enak...]

Apa yang dituturkan oleh Suryanto di atas, dapat ditarik pemahaman bahwa, kegiatan mengolah bahan adalah kegiatan latihan bersama mencari musik yang disesuaikan dengan naskah. Oleh karena itu, inti dari latihan adalah mengolah ide sang dalang, setelah setuju baru kemudian dilakukan praktik kompositoris, sebelum akhirnya berlanjut kepada ekplorasi bunyi dan mengemas bunyi musik.

\section{a. Mendiskusikan Naskah}

Bagian paling awal dalam tahapan mengolah bahan adalah, mendiskusikan naskah. Bagian ini dilakukan oleh dalang dengan para musisi. Mendiskusikan naskah tidak digelar secara formal atau serius seperti latihan menafsir gagasan cerita. Bagian ini dilakukan secara santai di mana saja, termasuk di angkringan, di rumah, atau kantin dan lain sebagainya. Keadaan itu dapat dilakukan lantaran aktivitas Dwi Suryanto dan para musisi terjalin atau saling bertautan sebagai seniman di lingkungan ISI Surakarta. Oleh karennya dialog atau diskusi ide dapat dilakukan di mana saja.

Naskah, tidak selalu berwujud teks yang sudah tertulis secara rapi dan terstruktur. Naskah yang dimaksud bisa saja berupa tulisan ala kadarnya, dan kadang masih bersifat abstrak di dalam benak DwiSuryanto. Diskusi yang dilakukan dengan para musisi berguna untuk mengembangkan cerita yang akan dibuat. Diskusi tersebut juga dalam rangka menjaring gagasan yang berbasis kekinian atau isu yang sedang news di lingkungan masyarakat dan sering dilakukan secara bercanda dan disambut gelak tawa. Naskah bisa lahir di mana saja, di wedangan, di perjalanan saat berangkat atau pulang dari pentas, serta percakapan melalui media sosial whatshapp.

Diskusi tentang naskah secara implisit adalah upaya untuk, menentukan tema-tema musik yang dibutuhkan, atau lagu-lagu yang pas untuk mebingkai sebuah adegan. Hal ini menjadi penting, karena kecocokan dalam kelompok seni sedikit banyak dicapai jika mempertimbangan semua personil sebagai sumber konten creator. Tema-tema kekinian, didapat DwiSuryanto melalui obrolan yang cair dengan para personil Congwayndut yang notabene diisi oleh anak-anak muda atau milenial.

\section{b. Eksplorasi Musikal}

Eksplorasi musikal, adalah bagian yang paling menentukan musik Congwayndut akan berwujud seperti apa. Bagian ini memerlukan waktu sekaligus tenaga yang lebih dari pada tahapan yang lain. Waktu dan tenaga sering terkuras pada saat eksplorasi musikal. Inti dari semua tahapan adalah bagian ini. Dengan kalimat lain, boleh dikatakan bahwa proses eksplorasi musikal adalah membentukan "nyawa".

Bagian ini dilakukan secara kolektif, kendati terjadi secara kolektif, ada aktor yang menjadi pemandunya termasuk Sang dalang berada dalam bagian pemandu. Eskplorasi dilakuakan diberbagai aspek, eksplorasi musikal, eskplorasi adegan, serta eksplorasi juker. Ekplorasi musikal meliputi ekplorasi musik keroncong, kontemporer, serta combo band.

\section{Mengemas Bahan}

Mengemas bahan adalah aktivitas latihan secara mendalam atau semacam gladi resik. Kegiatan ini tujuannya adalah untuk memeriksa kembali susunan alur mulai dari musik, cerita, hingga sistem perpindahan serta aransemen lagu-lagu yang akan disajikan. Proses mengemas bahan diikuti oleh seluruh personil yang ada. Ending dari mengemas bahan adalah cros chek sekaligus finishing terkait karya yang telah disusun, biasanya terjadi diskusi di akhir tahapan ini antara dalang, pemusik dan pembantu pertunjukan yang lainnya.

\section{Menyajikan Bahan}

Menyajikan bahan adalah aktivitas di atas panggung, dengan didukung oleh pendukung pergelaran seperti sound, lampu, layar atau kelir, didukung juga penonton sebagai tujuan utama pertunjukan Congwayndut menyampaikan edukasi khusunya anak muda dan lain sebagainya. Menyajikan bahan sama halnya dengan performer atau mengekspresikan karya seni yang telah disusun. 


\section{Aspek Musik}

Musik Congwayndut secara fungsi, sama persis sepertimusik pada teater, tidak seperti musik pada pakeliran wayang. Musik teater adalah musik yang digunakan untuk membangun suasana adegan. Selain itu, musik juga digunakan sebagai pembuka dan penutup sebuah pertunjukan teater. Beberapa literatur menjelaskan, dalam teater terdapat istilah musik dan bunyi. Musik adalah sistem kerja suara yang memiliki unsur ritme, harmoni dan melodi. Sementara efek bunyi adalah bebunyian yang tidak memiliki sifat musikal. Seperti suara tembakan, suara pintu terbuka dan tertutup, gonggongan anjing, dan lain sebagainya (Harymawan, 1993: 159). Kedudukan musik dalam Congwayndut juga sama seperti apa yang dijelaskan di atas, terdapat musik pembuka, musik ilustrasi, musik untuk peralihan adegan, efek bunyi dan musik penutup. Musik ilustrasi adalah berfungsi melatari sebuah adegan, gunanya membantu membangun suasana dramaturgi dalam adegan lewat suara. Misalnya adegan sedih, musik memproduksi suara dengan karakter sedih, seperti gesekan biola, tiupan saksofon yang lembut dan mendayu-dayu, petikan kecapi dengan nadanada minor yang memiliki kesan sedih, dan lain sebagainya. Lebih dari itu, dalam buku Dramaturgi dijelaskan, musik dapat membantu aktor dalam mendalami peran dalam setiap adegan (1993: 162).

Lebih lanjut seorang arranger (penata musik) juga diharapkan mengetahui sejarah dan perkembangan musik. Karena aliran Musik setiap masanya akan berbeda baik bentuk dan isi/nilainya, paling tidak menjadi bahan bacaan mengenai penggarapan sebuah karya, yang tujuannya untuk penyempurnaan dalam mengekplorasi dan mengaplikasikan bisa tepat sasaran dan menghadirkan suasana, aroma zaman yang dibutuhkan panggung pertunjukan.

\section{Manguyu-uyu}

Pertunjukan Congwayndut, musiknya dibagi atas beberapa bagian, yaitu: manguyuuyu, musik pembuka, musik ilustrasi, efek bunyi dan musik penutup. Manguyuuyu biasanya disajikan lagu-lagu keroncong dengan aranseman baru atau lagu populer yang digarap dengan model keroncong modern seperti: lagu Penasaran, All of Me, Ronggeng Imut, Kidung Rindu, Di Wajahmu, Sempurna, Ayo Ngguyu, dan lain sebagainya.

\section{Pembukaan}

Setelah manguyu-uyu biasanya pertunjukan dibuka dengan musik pembuka yaitu berjudul: Warunge Dibuka, digarap dengan model keroncong, combo band, dan swing. Aransemen tersebut dibuat untuk memeriahkan suasana pembukaan pertunjukan, suapa tercipta suasana gembira. Adapun penggalan teks vokalnya dalah sebagai berikut. Warunge dibuka...byak Dtoto sendok cangkire Panas kebul-kebul Nymleng tenan Wedang rondene Peteng remeng-remeng Manis manis pelayane Sentir lenggo potro Sing dipikir kok ora rumongso Esemane bakule gawe mriyang awaku Lirikane duh aduh gawe bingung atiku Iki piye iki piye...iki piye Sentir lengo potro sing dipikir kok ora rumongso

\section{Talu}

Setelah selesaimusik pembuka, pertunjukan dilanjutkan dengan adegan talu, yaitu sang dalang membuka sekaligus mengucap doa saat pertunjukan benar-benar di mulai. Adegan talu diawali dengan uluk salam dalang terhadap danyang yang menguasai lokasi pertunjukan, meskipun dikemas dengan canda dan tawa, tetapi esensi dari talu ada meminta izin kepada Tuhan dan yang roh-roh yang menguasai lokasi pertunjukan. Bagian ini biasanya diringi dengan musik talu yang berisikan teks vokal tentang pengenalan Congwayndut beserta personilya.

\section{Buka Kayon}

Selanjutnya musik talu, kemudian dilanjutkan dengan adegan buka kayon adegan buka kayon adalah adegan permulaan kehidupan atau cerita yang akan digelar. Bagian buka kayon ini biasanya diisi dengan musik garapan ala Congwayndut. 


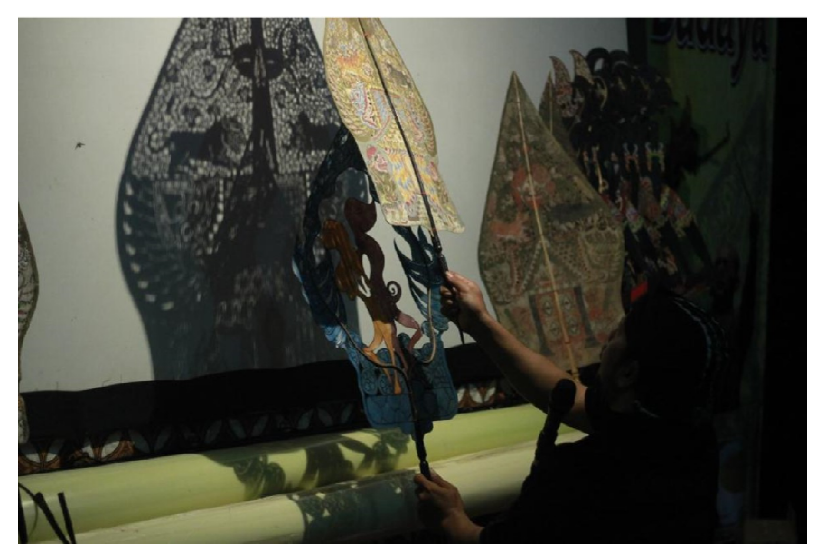

Gambar 6. Adengan buka kayon Congwayndut. (Foto: Joko Suyanto, 2018)

Musik buka kayon gabungan antara keroncong, tradisi Jawa dan combo band. Diawali dengan tabuhan unisono dari semua instrumen, disertai gerakan kayon yang dimainkan di depan lampu. Kemudian cak dan cuk dibunyikan secara statis dengan ritme yang cepat sebagai latar. Dipadu dengan aksen-aksen kendang Sunda, bersama dengan pukulan perkusi yang mengambil pola pada ketukan berat. Membuat musik yang disajikan memiliki dinamika yang kompleks.

Musik buka kayon memiliki karakter megah, rame, dan agung. Keagungannya ditambah suara koor vokal yang melantunkan menggunakan teknik suara semacam seriosa. Ditambah suara saxophone yang membingkai suara vokal, semakin menambah kesan elegan musik yang sajikan.

\section{Inti}

Adegan inti menceritakan tema besar lakon yang disajikan. Dalam bagian inti, di isi oleh musik ilustrasi dan musik transisi. Musik ilustrasi disajikan untuk membingkai sebuah adegan. Sementara musik transisi untuk menghantakan peralihan setting atau peralihan adegan. Musik ilustrasi dapat berbentuk lagu atau suasana musikal. Jika lagu disesuaikan dengan adegan yang sedang berlangsung. Misalkan adegan percintaan biasanya diilustrasikan dengan musik yang romantis, seperti alunan saxofon atau petikan gitar yang dapat menguatkan suasana dalam adegan.
Sementara musik peralihan, adalah musik garapan sendiri yang fungsinya mengantarkan setting adegan atau peralihan cerita. Dalam congwayndut tersedapat beberapa musik peralihan di antaranya: srepeg sarkliwon, srepeg minor, srepeg salam damai, dan sampak lu ro ji. Deretan musik peralihan tersebut bisa ditempatkan di mana saja dan dibagian peralihan adegan apa saja. Semua tergantung sang dalang yang menginginkan urutan sajiannya seperti apa. Begitu juga dengan musik ilustrasi, musik selalu menyiapkan paketan-paketan musik ilustrasi, nanti yang digunakan dalam pertunjukan musik yang seperti apa semua tergantung pengendali pertunjukan dan cerita yaitu dalang. Kendati demikian, sebelum pentas dimulai biasanya ada diskusi kecil atau hanya lewat group whatsapp, untuk menentukan musik dan lagu yang digunakan, serta urutan adegan beserta musik ilustrasi dan musik transisinya. Konsepnya sama seperti wayang klasik, hanya posisi musikya bisa dibolak-balik sesuai dengan kehendak dalang. Jadi tidak ada musik yang selalu pasti dalam adegan dan peralihan bagian tertentu.

\section{KESIMPULAN}

Musik keroncong dipilih oleh Congwayndut untuk menjadi musik pakeliran adalah karena persoalan eksklusivitas, yaitu keroncong secara bentuk musik jarang sekali digunakan sebagai musik perwayangan, teater atau dalam adegan apapun. Alasan tersebut lantas dijadikan tendensi yang kuat sebagai legitimasi bahwa musik keroncong juga mampu berkreativitas dalam dunia perwayangan. Proses penciptaan musiknya dilakukan dengan beberapa tahap yaitu: memilih bahan, mengolah bahan, mengemas bahan dan menyajikan bahan. Bahan yang dipilih meliputi: pertimbangan musisi dan garap musikal. Mengolah bahan meliputi: eksplorasi musik, latihan, sinkronisasi musik dengan adegan wayang, hingga pertimbangan aspek dramaturgi cerita. Memilih bahan dilakukan oleh Gendut Dalang yang disesuaikan dengan konsep wayang yang telah dipikirkan, yaitu keroncong modern.

Kemudian mengolah bahan, dilakukan dengan mempertimbangan musisi dan jenis musik 
apa yang memungkinkan digarap dengan bahan yang ada. Kebetulan bahan yang digunakan adalah keroncong modern, jadi sudah barang tentu jenis musik yang akan digarap adalah musik keroncong yang berbasis keroncong modern. Musik yang dimainkan dalam pegelaran wayang ini dibagi mejadi beberapa bagian yaitu: musik pembuka, musik ilustrasi, musik peralihan, efek bunyi dan musik penutup.

Langkah inovatif dari berbagai aspek tersebut adalah upaya konservasi kesenian khususnya kesenian wayang. Tidak berhenti sampai di situ, lebih jauh congwayndut adalah model seni yang secara konsep menerobos pakem, tetapi justru mampu membumikan kesenian wayang di ranah generasi tunas atau milenial. Selain itu, juga menjembatani penggemar wayang sebagai tontonan wayang yang efektif dan efisien.

\section{DAFTAR PUSTAKA}

Edi P Erwin. "Wayang Gendut Kreasi Humor yang Menjebol Pakem". Harian Kompas Edisi 31 Januari 2015.

Mack Dieter. 1995. Apresiasi Musik, Musik Populer. Yogyakarta: Yayasan Pustaka Nusatama.
Sadra I Wayan. "Lorong Kecil Menuju Susunan Musik" dalam Waridi e.d. Menimbang Pendekatan dan Pengkajian Musik Nusantara. Surakarta: Jurusan Karawitan ISI Press.

Sunarto Bambang. 2013. Epistemologi Penciptaan Seni. Yogyakarta: IDEA Sejahtera.

Sukerta, Pande, Made. 2011. Metode Penyusunan Karya Musik: Sebuah Alternatif. Surakarta: ISI Press Solo.

\section{DAFTAR NARASUMBER}

Dwi Suryanto, dalang Congwayndut, 38 tahu, alamat Perum Loh Agung, Jaten, Karamganyar.

Danis Sugiyanto, seniman keroncong sekaligus dosen Jurusan Karawitan ISI Surakarta,

Aji Agustian, salah satu musisi pada Congwayndut, 30 tahun, alamat Tempen, Pasar Kliwon, Surakarta

Muhammad Subhan, musisi Congwayndut, 34 tahun, 